\title{
Heterogeneous Nuclear Ribonucleoprotein D0
}

National Cancer Institute

\section{Source}

National Cancer Institute. Heterogeneous Nuclear Ribonucleoprotein DO. NCI

Thesaurus. Code C102832.

Heterogeneous nuclear ribonucleoprotein D0 (355 aa, $38 \mathrm{kDa}$ ) is encoded by the human HNRNPD gene. This protein is involved in both RNA transport and splicing. 